\title{
Kesesuaian ukuran soma pajeko dan kapalnya di Labuan Uki Kabupaten Bolaang Mongondow
}

\author{
The suitability of purse seine and its boat dimensions in Labuan Uki, \\ Bolaang Mongondow Regency
}

RAMlan PAPUTUNGAN*, Elof M. Katiandagho dan Meta S. SOMPIE.

Program Studi Pemanfaatan Sumberdaya Perikanan, Fakultas Perikanan dan Ilmu Kelautan, Universitas Sam Ratulangi, Manado 95115

\begin{abstract}
Purse seine fishery has been in North Sulawesi since several decades ago. In Labuan Uki, District of Lolak, Bolaang Mongondow there are 35 purse seine units. This research aimed to study the dimension suitability of bunt's length with net's length; net's length and width ( $k$ value); the length, width and depth of the boat; and bunt's length with boats' length. The results indicate that the average length of purse seine's bunt range from 10.50 to $20.25 \mathrm{~m}$ which does not reach 20 percent of the overall length of the net. The $k$ values range from 0.19 to 0.28 and fall in the range of $k$ standard. The length, width, and depth ratios of the boats are L/B 4.78-6.25, L/D 13.5-21.3, and B/D 2.4-4.4. These values do not match to the standard values. The ratio of bunt's length to boats' length is from 0.66 to 0.93 which does not comply with the standard ratio.
\end{abstract}

Keywords: suitability, dimension, boat, purse seine, Labuan Uki

\begin{abstract}
ABSTRAK
Perikanan "soma pajeko" (pukat cincin) sudah cukup lama ada di Sulawesi Utara. Di Labuan Uki Kecamatan Lolak Kabupaten Bolaang Mongondow terdapat alat tangkap soma pajeko sebanyak 35 unit. Penelitian ini bertujuan untuk mempelajari kesesuaian ukuran panjang kantong dengan panjang jaring, panjang jaring dengan lebar jaring (nilai $k$ ), panjang kapal, lebar kapal dan dalam kapal, serta panjang kantong dengan panjang kapal. Hasil penelitian menunjukkan bahwa panjang kantong soma pajeko berkisar antara 10,50 dan 20,25 m. Panjang kantong tersebut tidak mencapai $20 \%$ dari panjang keseluruhan alat tangkap. Nilai kesesuaian $k$ panjang dan lebar jaring berkisar antara 0,19 dan 0,28 berada dalam kisaran $k$ standar. Perbandingan antara panjang kapal, lebar kapal, serta dalam kapal adalah L/B 4,78-6,25, L/D 13,5-21,3, dan B/D 2,4-4,4. Nilai-nilai perbandingan tersebut tidak sesuai dengan standar. Perbandingan panjang kantong dan panjang kapal berkisar antara 0,66 dan 0,93 dan tidak sesuai dengan standar perbandingan.
\end{abstract}

Kata-kata kunci: kesesuaian, dimensi, kapal, pukat cincin, Labuan Uki

\section{PENDAHULUAN}

Sulawesi Utara merupakan salah satu daerah yang memiliki perairan pantai yang luas, dan "soma pajeko" (pukat cincin) berperanan penting dalam pemanfaatan sumberdaya perikanan pantai. Kesesuaian kapal dengan soma pajeko merupakan salah satu hal yang harus diperhatikan dalam kegiatan penangkapan.

\footnotetext{
* Penulis untuk penyuratan; email: ramlanpaputungan@yahoo.co.id
}

Menurut Katiandagho (2009), panjang shoulder adalah 70-80 \% dari panjang keseluruhannya. Kantong merupakan tempat terkumpulnya ikan pada waktu penarikan jaring. Agar supaya kantong terbuka dengan sempurna, maka panjangnya harus sesuai dengan panjang kapal soma pajeko, yaitu membentuk setengah lingkaran terhadap panjang kapal. Hal ini berarti bahwa panjang kapal merupakan garis tengah lingkaran. Jadi panjang kapal $=\pi \mathrm{R}$, dengan $\mathrm{R}=$ setengah LOA (length overall) kapal soma pajeko. 
Pada garis besarnya pukat cincin terdiri dari bagian-bagian yaitu sebagai berikut: kantong, badan jaring, sayap, pelampung, tali pelampung, pemberat, tali kolor, tali kekang dan salvage (Sudirman dan Mallawa, 2004). Perhitungan besarnya ukuran mata jaring memerlukan data ukuran minimum dari ikan secara komersial dan sifat dimensinya seperti panjang badan dari individu ikan. Seperti halnya semua alat tangkap ikan, inti merancang purse sine adalah untuk memilih/menentukan secara optimum bentuk alat sesuai dengan perilaku khusus ikan, karakter daerah yang akan ditebari jaring dan kekuatan teknis dari kapal (Fridman, 1988).

Perikanan soma pajeko sudah cukup lama berkembang di Sulawesi Utara ini. Selama ini belum diketahui dengan pasti apakah ada kesesuaian antara kapal dan alat soma pajeko yang dioperasikan, ukuran-ukuran alat dan ukuranukuran kapal. Oleh sebab itu perlu dilakukan penelitian untuk mempelajari segi teknis usaha tersebut, terutama yang menyangkut desain alat serta ukuran kapal yang digunakan. Penelitian ini bertujuan untuk mempelajari kesesuaian ukuran panjang kantong dan panjang jaring, panjang jaring dan lebar jaring (nilai $k$ ), panjang kapal, lebar kapal dan dalam kapal, panjang kantong dan panjang kapal.

\section{METODE PENELITIAN}

\section{Teknik pengambilan data}

Variabel yang diukur dalam penelitian ini adalah panjang jaring, lebar jaring, panjang kantong, panjang kapal (LOA, length overall), lebar kapal (B) dan dalam kapal (D). Pengukuran LOA dilakukan dari ujung buritan sampai ujung haluan, pengukuran lebar kapal dilakukan pada lebar terlebar yang diukur hingga kulit terluar dari kapal, dan pengukuran dalam kapal dilakukan dari base line (garis dasar) hingga free board deck pada bagian midship.

\section{Teknik analisa data}

Untuk melihat kesuaian ukuran soma pajeko, maka data ukuran dibandingkan dengan ukuran standar, yakni:

- Nilai $k$, yaitu perbandingan panjang jaring dan lebar jaring yang bernilai $0,08-0,20$ atau sampai 0,30 (Katiandagho, 1985).
- Perbandingan panjang kantong dengan panjang jaring, dengan nilai standar sebesar $20 \%$. (Katiandagho, 2009)

- Perbandingan panjang dengan lebar kapal L/B $=4,28$, perbandingan panjang kapal dan dalam kapal $\mathrm{L} / \mathrm{D}=9,63$, dan perbandingan lebar kapal dan dalam kapal B/D = 2,24 (Suzuki, 1978).

- Perbandingan antara panjang kantong dengan panjang kapal umumnya adalah $(1,5-2,0): 1$ (Katiandagho, 2009).

\section{HASIL DAN PEMBAHASAN}

\section{Deskripsi unit penangkapan Alat tangkap ikan}

Soma pajeko yang ada di Kecamatan Lolak pada umumnya mengikuti tipe Jepang yaitu berbentuk $\mathrm{U}$, dengan bagian kantong lebih dalam daripada bagian sayap dan ukuran tali pelampung lebih kecil dari ukuran tali pemberat.

Konstruksi pukat cincin tipe Jepang ini terdiri dari jaring, tali ris atas, tali pelampung, tali ris bawah, tali samping, tali pemberat, tali tarik, tali cincin, bridle, pelampung, pemberat dan cincin. Selain itu terdapat juga bagian yang disebut selvedge yang berfungsi sebagai penguat dan dipakai pada bagian sisi jaring.

\section{Bahan jaring}

Material jaring yang digunakan pada ke enam alat pukat cincin, umumnya menggunakan material polyamide continuous filament $(\mathrm{PA} \mathrm{cf})$ untuk bagian kantong, perut, bahu dan sayap, dan polyethylene continuous filament $(\mathrm{PE} \mathrm{cf})$ untuk bagian selvedge. Untuk bagian kantong menggunakan bahan PA cf $210 \mathrm{D} \times 18$, untuk soma pajeko Fitri dan Bintang Bahari, PA cf $210 \mathrm{D} \times 21$ untuk soma pajeko Vina sedangkan soma pajeko Sinar Lestari 04, 05 dan 06 menggunakan dua ukuran benang yaitu PA cf $210 \mathrm{D} \times 18$ dan PA cf $210 \mathrm{D} \times 24$. Untuk bagian perut, bahu dan sayap, ke enam alat tersebut menggunakan ukuran benang yang sama yaitu PA cf $210 \mathrm{D} \times 15$, PA cf $210 \mathrm{D} \times 12$ dan PA cf $210 \mathrm{D} \times 9$. Untuk bagian selvedge semuanya menggunakan bahan PA cf $210 \mathrm{D} \times 24$. Jika ukuran benang besar maka tahanan air juga besar.

Ukuran mata yang digunakan berbeda pada tiap bagiannya. Pada bagian kantong umumnya menggunakan ukuran mata $25,4 \mathrm{~mm}$, pada bagian perut $31,75 \mathrm{~mm}$, bagian bahu $38,1 \mathrm{~mm}$ bagian 
sayap 50,8 mm, sedangkan bagian selvedge 50,8 $\mathrm{mm}$. Soma pajeko hanya untuk ikan pelagis kecil.

\section{Tali temali}

Tali yang digunakan oleh keenam soma pajeko adalah PE, namun diameter benangnya berbeda untuk setiap bagian. Tali penarik terdiri dua bagian yang masing-masing diikatkan pada bagian samping jaring, tali pelampung, tali ris atas. Tali penarik ini berfungsi untuk menarik pelampung, tali penarik yang biasa digunakan tali nomor 18 .

Tali pelampung umumnya menggunakan tali nomor 12 yang diikatkan sejajar dengan tali ris. Tali ris ini berfungsi untuk menggantungkan jaring. Ukuran tali yang digunakan tali ris untuk semua soma pajeko adalah nomor 10 .

Tali samping terdiri dari 4 buah, yaitu 2 buah pada samping kanan jaring kemudian 2 buah pada samping kiri jaring, dengan ukuran tali yaitu nomor 10. Tali samping ini berfungsi untuk mengikatkan jaring bagian samping.

Tali ris bawah maupun tali pelampung menggunakan ukuran tali nomor 10 . Tali ris bawah berfunsi untuk mengikatkan jaring bagian bawah. Tali ris ini diikatkan sejajar dengan tali pemberat

Tali bridles menggunakan nomor 12 yang berfungsi untuk mengikatkan cincin dengan badan jaring. Jumlah tali bridles ini disesuaikan dengan jumlah cincin yang digunakan.

Tali cincin berfungsi untuk menarik cincin sehingga cincin akan berkumpul ditengah dan jaring akan membentuk kantong. Ukuran tali cincin yang digunakan di setiap kapal berbedabeda. KM. Fitria dan KM. Bintang Bahari menggunakan tali nomor. 20, KM. Vina 03 menggunakan tali nomor 24, sedangkan KM. Sinar Lestari 04, 05, 06 menggunakan tali nomor 32.

\section{Pelampung}

Pelampung yang dipakai semua terbuat dari bahan vynil yang berbentuk bulat lonjong. Ukuran pelampung untuk setiap kapal berbeda-berbeda. Untuk soma pajeko Vina, Bintang Lestari dan Fitria menggunakan pelampung type F 803 A, sedangkan soma pajeko Sinar Lestari 04, 05 dan 06 menggunakan dua type yaitu F 803 A dan D $8 \mathrm{~T}$.

\section{Pemberat}

Pemberat yang digunakan oleh keenam soma pajeko terbuat dari bahan timah hitam $(\mathrm{Pb})$, yang berbentuk silinder dan mempunyai ukuran dan berat yang berbeda yaitu KM. Fitria menggunakan ukuran $50 \times 30 \times 13$ dan berat $325 \mathrm{gr}, \mathrm{KM}$. Vina dan KM. Sinar Lestari 04 menggunakan ukuran $55 \times 30 \times 13$ dan berat 325 gr, KM. Bintang Bahari, dan KM. Sinar lestari 05, 06 menggunakan ukuran $50 \times 30 \times 13$ dan berat 300 gr.

\section{Cincin}

Cincin yang digunakan pada keenam soma pajeko terbuat dari bahan kuningan $(\mathrm{Br})$, bentuknya bulat dan mempunyi ukuran dan berat yang sama yaitu ukuran $150 \times 120 \times 15$ dan berat $650 \mathrm{gr}$.

\section{Kapal penangkap ikan}

Kapal yang digunakan dari keenam soma pajeko ini umumnya terbuat dari kayu tipe lambut dengan lambung kapal model $\mathrm{U}$ dan mempunyai ukuran berbeda baik panjang, lebar dan dalam kapal. Ukuran ini sangat perlu karena berpengaruh pada stabilitas kapal. Panjang kapal berkisar dari 16,0 m sampai 30,0 m, lebar kapal dari 1,8 m sampai 4,8 $\mathrm{m}$ dan dalam kapal dari $0,75 \mathrm{~m}$ sampai dengan 4,4 m. Ukuran kapal selengkapnya dapat dilihat pada Tabel 1.

Tabel 1. Ukuran kapal dan jaring

\begin{tabular}{|c|c|c|c|c|c|c|c|c|}
\hline \multirow[t]{2}{*}{ NO } & \multirow[t]{2}{*}{ NAMA } & \multicolumn{3}{|c|}{ KAPAL } & \multicolumn{4}{|c|}{ JARING } \\
\hline & & $\begin{array}{c}\text { Panjang } \\
(\mathrm{m})\end{array}$ & $\begin{array}{l}\text { Lebar } \\
(\mathrm{m})\end{array}$ & $\begin{array}{c}\text { Dalam } \\
(\mathrm{m})\end{array}$ & $\begin{array}{c}\text { Panjang } \\
(\mathrm{m})\end{array}$ & $\begin{array}{l}\text { Lebar } \\
(\mathrm{m})\end{array}$ & $k=1 / L$ & $\begin{array}{c}\text { Panjang } \\
\text { Kantong (m) }\end{array}$ \\
\hline 1. & KM. Fitria & 16,00 & 3,00 & 0,75 & 300,00 & 56,25 & 0,19 & 10,50 \\
\hline 2. & KM. Bintang Bahari & 18,20 & 3,80 & 0,86 & 320,00 & 70,00 & 0,22 & 12,00 \\
\hline 3. & KM. Vina 03 & 22,50 & 4,00 & 1,60 & 345,00 & 98,25 & 0,28 & 20,25 \\
\hline 4. & KM. Sinar Lestari 04 & 23,70 & 4,40 & 4,40 & 409,50 & 90,00 & 0,22 & 22,00 \\
\hline 5. & KM. Sinar Lestari 06 & 27,00 & 4,80 & 2,00 & 450,00 & 105,00 & 0,23 & 18,00 \\
\hline 6. & KM. Sinar Lestari 05 & 30,00 & 4,80 & 2,00 & 474,00 & 120,00 & 0,25 & 18,00 \\
\hline
\end{tabular}




\section{Kesesuaian panjang kantong dengan panjang ja- ring}

Katiandagho (2009) menyatakan bahwa untuk penangkapan tipe satu kapal, panjang kantong yaitu harus $20 \%$ dari panjang jaring. Dari ke enam soma pajeko diperoleh panjang kantong tidak mencapai $20 \%$ dari panjang jaring. Hal ini berarti panjang kantong untuk keenam alat tersebut tidak memenuhi syarat karena bagian kantong kurang panjang sehingga luas area untuk mengurung gerombolan ikan terlalu kecil. Soma pajeko ini dioperasikan pada malam hari dan banyak terdapat ikan yang terbelit pada mata jaring di luar bagian kantong serta proses penangkapan yang dilakukan biasa memakan waktu yang panjang atau lama. Untuk itu, sebaiknya panjang kantong ke enam alat soma pajeko harus ditambah dan disesuaikan dengan ukuran standar yang dikemukakan oleh Katiandagho (2009).

\section{Kesesuaian panjang jaring dengan lebar jaring}

Nilai $k$ merupakan perbandingan antara lebar jaring (l) dengan panjang jaring (L), kemudian setelah perbandingan tersebut dianalisa diperoleh nilai $k$ berkisar antara 0,19 dan 0,28 . Hasil perhitungan nilai $k$ ini menunjukkan kesesuaian dengan perbandingan yang diberikan oleh Katiandagho (1985) sebesar 0,20 sampai 0,30 untuk penangkapan ikan-ikan pelagis pada malam hari. Kesesuaian perbandingan panjang dan lebar ini menunjukkan bahwa jaring dapat di operasikan dengan baik.

\section{Kesesuaian panjang kapal, lebar kapal dan da- lam kapal}

Perbandingan antar ukuran utama kapal L/B berkisar antara 4,78 dan 6,25, L/D berkisar antara 13,5 dan 21,3, dan B/D berkisar antara 2,4 dan 4,4. Nilai-nilai perbandingan ini tidak sesuai dengan standar yang yang diberikan Suzuki (1978).
Kesesuaian panjang kantong dengan panjang kapal

Menurut Katiandagho (2009), kantong merupakan tempat terkumpulnya ikan pada waktu penarikan jaring. Agar supaya kantong terbuka dengan sempurna, maka panjangnya harus sesuai dengan panjang kapal soma pajeko, yaitu membentuk setengah lingkaran terhadap panjang kapal. Hal ini berarti bahwa panjang kapal merupakan garis tengah lingkaran. Perbandingan yang umum antara panjang kantong dan panjang kapal adalah $(1,5-$ 2,0):1.

Perbandingan panjang kantong dan panjang kapal dari keenam alat tersebut berkisar dari 0,66 sampai dengan 0,93. Perbandingan ini terlalu jauh berbeda dengan ketentuan yang ada yaitu 1,52,0):1. Kesesuaian antara ukuran kapal dan ukuran jaring yang diteliti dapat dilihat pada Tabel 2 .

\section{KESIMPULAN}

Alat tangkap soma pajeko mempunyai panjang kantong rata-rata tidak mencapai $20 \%$ dari panjang keseluruhan alat tangkap. Sedangkan untuk panjang jaring dan lebar jaring rata-rata setiap kapal sesuai dengan standar $k=0,20-0,30$.

Nilai pada panjang kapal, lebar kapal, serta dalam kapal didapati tidak sesuai dengan standar $\mathrm{L} / \mathrm{B}=4,28, \mathrm{~L} / \mathrm{D}=9,63$ dan $\mathrm{B} / \mathrm{D}=2,24$. Hal ini disebabkan karena kurangnya pengetahuan nelayan dan pembuatan hanya didasarkan pada pemikiran sendiri, tidak didasarkan dengan standar yang ada.

Perbandingan panjang kantong dan panjang kapal dari keenam alat tersebut menunjukkan ketidaksesuaian dengan kisaran perbandingan panjang kantong dengan panjang kapal dari 0,66 sampai dengan 0,93 dan lebih rendah dari standar perbandingan yaitu $(1,5-2,0): 1$.

Tabel 2. Kesesuaian ukuran kapal dan ukuran jaring yang seharusnya

\begin{tabular}{|c|c|c|c|c|c|c|c|}
\hline \multirow[t]{2}{*}{ NO } & \multirow[t]{2}{*}{ NAMA } & \multicolumn{3}{|c|}{ KAPAL } & \multicolumn{3}{|c|}{ JARING } \\
\hline & & $\begin{array}{c}\text { Panjang } \\
(\mathrm{m})\end{array}$ & $\begin{array}{c}\text { Lebar } \\
(\mathrm{m})\end{array}$ & $\begin{array}{c}\text { Dalam } \\
(\mathrm{m})\end{array}$ & $\begin{array}{c}\text { Panjang } \\
(\mathrm{m})\end{array}$ & $\begin{array}{c}\begin{array}{c}\text { Lebar } \\
(\mathrm{m})\end{array} \\
\end{array}$ & $\begin{array}{c}\text { Panjang } \\
(\mathrm{m})\end{array}$ \\
\hline 1. & KM. Fitria & 16,00 & 3,70 & 1,66 & 125,70 & 31,42 & 25,14 \\
\hline 2. & KM. Bintang Bahari & 18,20 & 4,25 & 1,88 & 142,85 & 35,71 & 28,57 \\
\hline 3. & KM. Vina 03 & 22,50 & 5,25 & 2,33 & 176,65 & 44,15 & 35,33 \\
\hline 4. & KM. Sinar Lestari 04 & 23,70 & 5,54 & 2,46 & 186,05 & 46,51 & 37,21 \\
\hline 5. & KM. Sinar Lestari 06 & 27,00 & 6,30 & 2,80 & 211,95 & 52,98 & 42,39 \\
\hline 6. & KM. Sinar Lestari 05 & 30,00 & 7,00 & 3,10 & 235,50 & 58,87 & 47,10 \\
\hline
\end{tabular}




\section{DAFTAR PUSTAKA}

Fridman, A.L. 1988. Perhitungan dalam Merancang Alat Penangkap Ikan. Balai Pengembangan Penangkapan Ikan, Semarang.

Katiandagho, E.M. 2009. Purse Seine. Laboratorium Teknologi Penangkapan Ikan, Universitas Sam Ratulangi, Manado.
Sudirman, H. dan A. Mallawa. 2004. Teknik Penangkapan Ikan. Rineka Cipta. Jakarta.

Suzuki, O. 1978. Fishing Gear and Methods. Dalam: Handbook for Fisheries Scientists and Technologists. TRB.No.3. SEAFDEC Training Department, Thailand. 